\title{
Simple and Sensitive Electroanalytical Method for the Determination of Ascorbic Acid in Urine Samples Using Measurements in an Aqueous Cationic Micellar Medium
}

\author{
Alaécio Pinheiro dos Reis,* César Ricardo Teixeira Tarley, ${ }^{* *}$ Lucilene Dornelles Mello,* \\ and Lauro Tatsuo KUBOTA*
}

*Instituto de Química, UNICAMP, P. O. Box 6154, Campinas, SP, 13083-970, Brazil

**Departamento de Ciências Exatas, Unifal-MG, Alfenas, MG, 37130-000, Brazil

\begin{abstract}
An electroanalytical study for the amperometric determination of ascorbic acid (AA) in a human urine sample at a bare glassy carbon electrode using the CPC (cetylpyridinium chloride) surfactant is described. Under the optimized conditions of $E_{\mathrm{pa}}, I_{\mathrm{pa}}, \mathrm{CPC}$ concentration and $\mathrm{pH}$, the oxidation peak potential of the AA shifts towards a less positive potential, and the peak current increase in a significant way in the presence of the surfactant. Under the best conditions, the method provided a linear calibration curve to AA in a $0.1 \mathrm{~mol} \mathrm{~L}^{-1}$ phosphate buffer solution $(\mathrm{pH} \mathrm{7.0)}$ in the concentration range from $5.0 \times 10^{-7}$ up to $4.3 \times 10^{-4} \mathrm{~mol} \mathrm{~L}^{-1}$, with a detection limit of $2.0 \times 10^{-7} \mathrm{~mol} \mathrm{~L}^{-1}$ and a high correlation coefficient $(r=$ 0.9996). The recovery test presented values of $98-105 \%$, suggesting a great potential of the proposed method for AA determination in complex samples, such as urine.
\end{abstract}

(Received February 18, 2008; Accepted May 29, 2008: Published December 10, 2008)

\section{Introduction}

Ascorbic acid ( $\gamma$-lactone of 2-desoxy-2-keto-L-gulonic acid or vitamin $\mathrm{C}$ ) is a powerful water-soluble vitamin (abbreviation AA). It is an effective reducing agent, generally used as an antioxidant in pharmaceutical preparations and food, preventing color changes and alterations of aroma and flavor as well as extending the storage time of products. ${ }^{1}$ This vitamin is among electroactive compounds of major biological importance, and plays a key role in protection against biological oxidation processes participating in many metabolic reactions. ${ }^{2}$ AA has also been used in the treatment and prevention of common the cold, mental illness and infertility, and offers protection against cancer agents. ${ }^{3}$ Traditionally, AA has been used in clinical in the treatment and prevention of scurvy, but it is also important in regulating the immunologic system and in tissue reconstruction, which assists the formation of collagen. ${ }^{4,5}$ Although many people take an AA dosage more than the necessary, it can be a problem because high levels of AA frequently have been associated to diarrhea, gastric irritation and renal disease. ${ }^{6}$ Thus, it is important to determine AA in such biological fluids as urine to monitor excess of vitamin $\mathrm{C}$.

Many analytical procedures have been proposed to quantify AA, including enzymatic analysis, ${ }^{7}$ fluorometry, ${ }^{8}$ chromatography, ${ }^{9} \quad$ titrimetry, $^{10}$ spectrophotometry ${ }^{11}$ and electrochemical methods. ${ }^{12}$ Among these, electrochemical approaches have proved to be advantageous because of their simplicity, high sensitivity and rapidity. ${ }^{13-15}$

The electrochemical determination of AA in complex matrices with conventional electrode materials in samples with low $\mathrm{pH}$,

† To whom correspondence should be addressed.

E-mail: ctarleyquim@yahoo.com.br for instance, is difficult because the fouling by oxidation and formed interferent products. ${ }^{16}$ Currently, strategies to quantify AA have used chemically modified electrodes that reduce the overpotential to oxidize AA. ${ }^{17,18}$ Recent research on chemically modified electrodes, especially by Thangamuthu and coworkes, ${ }^{19}$ has shown that a glassy carbon electrode (GCE) modified with $\mathrm{Mo}(\mathrm{CN})_{8}{ }^{4}$-incorporated-poly(4-vinylpyridine) $\left(\mathrm{PVP} / \mathrm{Mo}(\mathrm{CN})_{8}{ }^{4-}\right)$ is an efficient electrocatalytic electrode for AA oxidation. The method was sucessfully applied for AA determination in fruit juice and pharmaceuticals. In another work, a novel vanadium oxide polypropylene carbonate modified glassy carbon electrode was developed and used to measure AA. The electrode was prepared by casting a mixture of vanadium tri(isopropoxide) oxide $\left(\mathrm{VO}\left(\mathrm{OC}_{3} \mathrm{H}_{7}\right)_{3}\right)$ and poly(propylenecarbonate) (PPC) onto the surface of a glassy carbon electrode. The method has been successfully applied to the determination of AA in fruits. ${ }^{20}$ The use of pontentiometric sensors has also been used for AA determination within a wide linear concentration range, according to Wang and co-workers, ${ }^{21}$ in which the approach focused on the development of a solid-contact potentiometric sensor based on cobalt phthalocyanine nanoparticles (NanoCoPc) as an ionophore. Other electrochemical approaches are based on immobilizing a bis(2,2'-bipyridyl)copper(II) complex in a self-assembled monolayer (SAM) of 3mercaptopropionic acid.22 In spite of the fact that many chemically modified glassy carbon electrodes have been developed, most of these methods require skilled personnel for building modified electrodes and, as consequence, are not suitable for routine analysis, and in many cases exhibit poor reproducibility, stability and short lifetimes of the electrodes. These problems have been poorly solved, and thus justifying the search for improved methods. In this context, the use of a micellar environment in electrochemical determination at a bare electrode appears to be an attractive way for the development of 


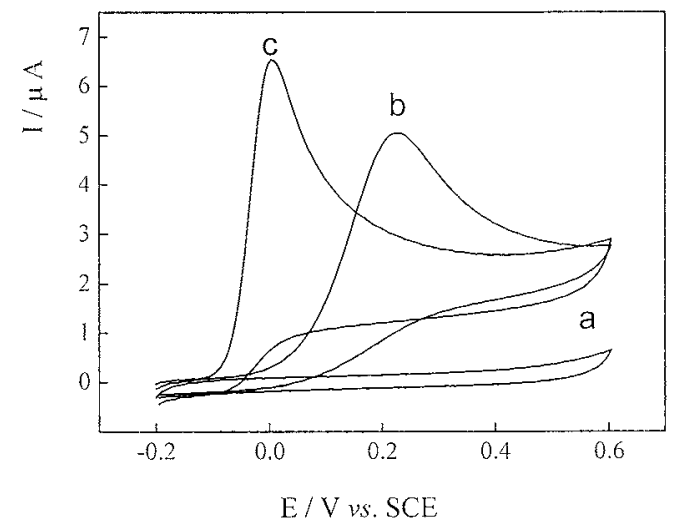

Fig. 1 Cyclic voltammograms of $200 \mu \mathrm{mol} \mathrm{L}^{-1} \mathrm{AA}$ recorded at a glassy carbon electrode in $0.1 \mathrm{~mol} \mathrm{~L}^{-1}$ phosphate buffer $(\mathrm{pH} 7.0)$. Scan rate, $100 \mathrm{mV} \mathrm{s}^{-1}$. Voltammogram: a, blank; b, in the absence; $\mathrm{c}$, in the presence of $1.0 \mathrm{mmol} \mathrm{L}^{-1} \mathrm{CPC}$.

a simple, reliable and friendly electrochemical method for AA determination. This very promising strategy, which is still little exploited, is based on using micellar media (composed by surfactants). A micellar system may mediate a catalytic reaction and show properties that are attractive for use in electrochemistry. It can be cited that the solubilization of electrochemically active compounds in micellar aggregates changes the redox potential, the charge transfer and the diffusion coefficients of the electrode processes, as well as the stability of electrogenerated intermediates and electroactive products derived from electrochemical reactions. ${ }^{23-26}$ Despite this, a few reports concerning the application of micellar systems have pointed out the electrochemical determination of important biological molecules like AA.

Szymula and Narkiewicz-Michalez ${ }^{27}$ studied the electrochemical oxidation behavior of AA in aqueous solution with the surfactants SDS, AOT (anionic), Triton X-100 (nonionic) and CTAB (cationic). It was verified that surfactants shift the oxidation peak potential of the AA, and change the peak current value, mainly due to the surfactant film formed at the electrode/solution interface. Based on this fact, the negatively charged AA has a tendency to accumulate in the positively charged crown of the micelles, which enhances the rate of oxidation, and consequently causes an increase in the peak current. The study revealed that the micellar system formed by $\mathrm{CTAB}$ promotes the oxidation of AA by lowering its oxidation potential and increasing the peak current. It was also observed that anionic and nonionic micelles have a small influence on the kinetics of AA oxidation. In the case of an SDS micellar solution, the oxidation process was slower than in the absence of a surfactant. In this direction, this paper comprises the development of a simple, selective and sensitive method for the amperometric determination of AA in urine samples at a bare glassy carbon electrode using a cetylpyridinium chloride surfactant medium.

\section{Experimental}

\section{Apparatus}

Measurements were carried out using a conventional electrochemical cell based on a saturated calomel electrode (SCE) as a reference, platinum wire as an auxiliary and a glassy carbon electrode (GCE) as a working electrode. The used GCE

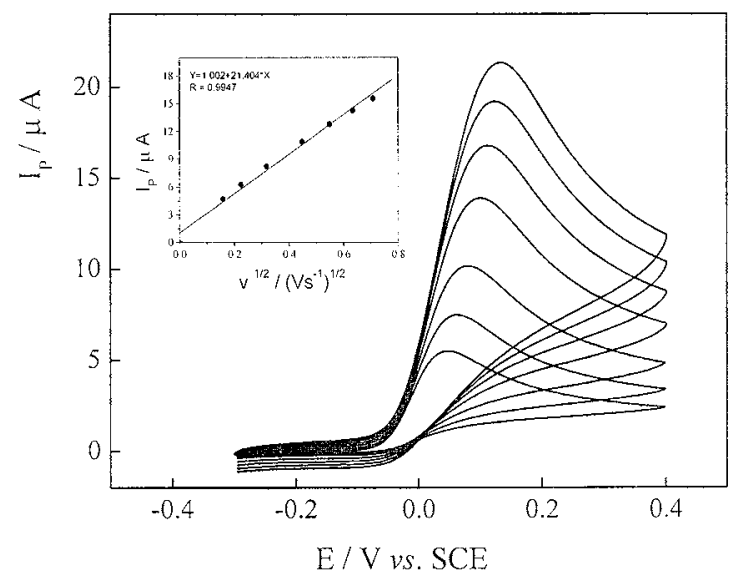

Fig. 2 Cyclic voltammograms of $200 \mu \mathrm{mol} \mathrm{L} \mathrm{L}^{-1} \mathrm{AA}$ recorded at a glassy carbon electrode in $0.1 \mathrm{~mol} \mathrm{~L}^{-1}$ phosphate buffer $(\mathrm{pH} 7.0)$ containing $1.0 \mathrm{mmol} \mathrm{L}^{-1} \mathrm{CPC}$ at different scan rates. Potential scan rates from down to up are: 25, 50, 100, 200, 300, 400 and $500 \mathrm{mV} \mathrm{s}^{-1}$, respectively. The inset is a plot of the peak current $(I / \mu \mathrm{A})$ versus the square root of the scan rate $\left(v^{1 / 2}\right)$

$\left(A=0.071 \mathrm{~cm}^{2}\right)$ was polished with $\mathrm{Al}_{2} \mathrm{O}_{3}(0.5 \mu \mathrm{m})$, followed by rinsing with deionized water, and then sonicated using alcohol and deionized water mixture solution for $2 \mathrm{~min}$.

A potentiostat from Eco Chemie Autolab ${ }^{\circledR}$ PGSTAT30 connected to a PC (software GPES 4.8) was employed in the measurements. Electrochemical experiments were performed at room temperature and purging $\mathrm{N}_{2}$ under an electrochemical cell.

\section{Reagents}

Ascorbic acid and cetylpyridinium chloride (CPC) were used without further purification, and were purchased from Sigma (St. Louis, USA). All aqueous solutions were prepared using ultrapure water $(\rho>18 \mathrm{M} \Omega / \mathrm{cm})$ from a Milli-Q System (Millipore, System). All other chemicals used were of analytical grade reagents. The supporting electrolyte for all experiments, unless specified otherwise, was a $0.1 \mathrm{~mol} \mathrm{~L}^{-1}$ phosphate buffer solution $(\mathrm{pH}=5.0-8.0)$.

\section{Results and Discussion}

\section{Electrochemical oxidation of AA in a micellar solution}

Figure 1 shows the electrooxidation of AA at a glassy carbon electrode in a phosphate buffer solution ( $\mathrm{pH} 7.0)$ in the absence and the presence of CPC. Voltammetric curves of AA recorded in the absence of CPC (Fig. 1b) show an oxidation peak at around $+0.23 \mathrm{~V}$, at which the electron-transfer rate is rather sluggish, owing to fouling of the electrode surface by adsorption of the oxidation product of AA. According to literature, the oxidation process of $\mathrm{AA}$ in an aqueous solution with a $\mathrm{pH}$ value higher than the first $\mathrm{p} K_{\mathrm{a}}$ of $\mathrm{AA}$ (first $\mathrm{p} K_{\mathrm{a}} 4.17$ ) involves less of a single proton and two electrons. ${ }^{28}$ The presence of CPC in solution promotes an increase in the electron transfer for the oxidation of AA (Fig. 1c), as observed by shift at the anodic peak potential of the compound to less positive values (measured peak potential around $0.0 \mathrm{~V}$ ), as well as an increase in the measured peak current. This effect can be explained by considering the AA under the studied $\mathrm{pH}$ condition ( $\mathrm{pH} 7.0)$ where it is as a monoprotonated ascorbate anion; in a micellar medium this dissociated form is established by an electrostatic interaction with a cationic surfactant CPC. The changes of the 


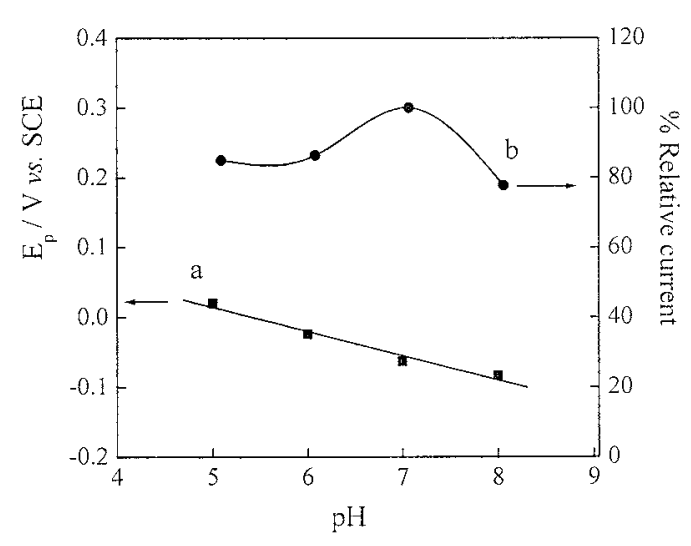

Fig. 3 Effect of the pH on (a) the peak current and (b) the peak potential for the oxidation of $200 \mu \mathrm{mol} \mathrm{L}^{-1} \mathrm{AA}$ at a glassy carbon electrode in the presence of $1.0 \mathrm{mmol} \mathrm{L}^{-1} \mathrm{CPC}$.

redox parameters are attributed to a surface effect, i.e., it is well established that surfactants in a solution promote aggregation as well as the adsorption and organization on the electrode surface to form surfactant films..$^{26,29-31}$ In order to investigate that the films of CPC adsorbed on the electrode surface are the responsible for the electrochemical behavior observed in the presence of CPC, an investigation of preparing the film using concentrated CPC solution was carried out. The film was prepared in a concentrated CPC solution $\left(1.0 \mathrm{~mol} \mathrm{~L}^{-1}\right)$ before the measurement. The electrode was immersed in this solution during several minutes, followed by washing with water. Next, cyclic voltammetry was performed in the presence of AA without $\mathrm{CPC}$ in the medium, and the result was similar to those obtained in the presence of $\mathrm{CPC}$, thus indicating, in fact, $\mathrm{CPC}$ film formation on the electrode surface.

Figure 2 shows cyclic voltammograms of AA in a phosphate buffer solution containing $1.0 \mathrm{mmol} \mathrm{L}^{-1}$ cationic surfactant $\mathrm{CPC}$ at different scan rates, and it is clearly observed that the peak currents for AA are proportional to the square root of the scan rate in the range $25-700 \mathrm{mV} \mathrm{s}^{-1}$ (Fig. 2, inset), thus indicating that the electrode reaction is controlled by difussion. ${ }^{16,32,33}$ Another important observation is the oxidation peak potential, which shifts positively, increasing the scan rates, indicating a kinetic limitation towards the electrooxidation reaction of AA in cationic micelles environments. In order to comprove these considerations, the apparent diffusion coefficient of the AA in micellar medium was estimated. The relation between the anodic oxidation peak current, $i_{\mathrm{pa}}(\mathrm{mA})$, the apparent diffusion coefficient of the electroactive specie, $D_{0}\left(\mathrm{~cm}^{2} \mathrm{~s}^{-1}\right)$, and the scan rate, $v\left(\mathrm{~V} \mathrm{~s}^{-1}\right)$, is given by

$$
i_{\mathrm{pa}}=(2.99 \times 105) n \alpha^{1 / 2} A C_{0} D_{0}^{1 / 2} v^{1 / 2},
$$

where $n$ is the number of electrons exchanged in oxidation, $\alpha$ the transfer coefficient, $A$ the apparent surface area of the electrode $\left(\mathrm{cm}^{2}\right)$, and $C_{0}$ the concentration of the electroactive specie. The transfer coefficient, $\alpha$, for an irreversible process can be calculated by an equation according to a reference: ${ }^{34}$

$$
\alpha=\frac{47.7}{E_{\mathrm{pa}}-E_{\mathrm{p} / 2}}
$$

Here, $E_{\mathrm{pa}}(\mathrm{mV})$ is the anodic peak potential and $E_{\mathrm{pa} / 2}$ is the halfwave potential. Thus, the apparent diffusion coefficient $\left(D_{0}\right)$ for AA was found to be $2.15 \times 10^{-11} \mathrm{~cm}^{2} \mathrm{~s}^{-1}$. Considering that $D_{0}$ can be an average value of the diffusion process in the bulk,

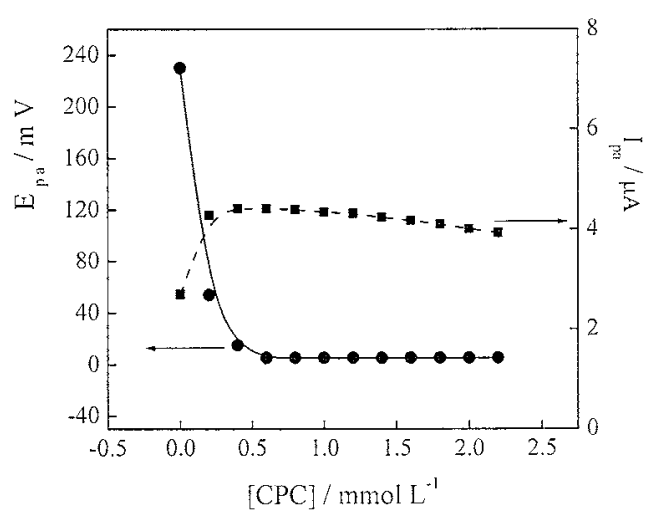

Fig. 4 Variation of the anodic peak potential $\left(E_{\mathrm{pa}}\right)$ (solid line) and that of the anodic peak current $\left(I_{\mathrm{pa}}\right)$ (dashed line) of AA at a glassy carbon electrode with the surfactant concentration. The experimental conditions were the same as indicated in Fig. 1.

within the surfactant aggregates in solution and the surfactant layer adsorbed at the surface of the electrode, it is possible to conclude that the interaction of CPC with the electrode surface could contribute to a decrease the efficient transport of AA to the electrode surface, thus explaining the low diffusion coefficient found.

\section{Effect of the $\mathrm{pH}$ on $\mathrm{AA}$ oxidation}

Figure 3 shows the effect of the $\mathrm{pH}$ on the electrochemical behavior of AA examined by cyclic voltammetry over the $\mathrm{pH}$ range from 5 to 8 at a glassy carbon electrode in the presence of CPC. All peak potentials of AA shifted toward more negative values by increasing the solution $\mathrm{pH}$ ( 5 to 8$)$. This behavior can be explained as being due to the deprotonation step involved in the oxidation process, which is facilitated at a higher $\mathrm{pH}$ value. ${ }^{35}$ However, the peak current for AA, in the presence of $1.0 \mathrm{mmol}$ $\mathrm{L}^{-1} \mathrm{CPC}$, reaches a maximum value at $\mathrm{pH}$ 7.0. For higher $\mathrm{pH}$ values, the response probably decreases due to the instability of the AA molecule. Thus, a $0.1 \mathrm{~mol} \mathrm{~L}^{-1}$ phosphate buffer at $\mathrm{pH}$ 7.0 was chosen as the supporting electrolyte in this work.

\section{Effect of the CPC concentration on AA oxidation}

Figure 4 shows the influence of the surfactant concentration variation on the oxidation process of AA. The oxidation potential of AA decreases with increasing the surfactant concentration, and the vicinity of CMC (critical micellar concentration) reaches a plateau corresponding to $0.020 \mathrm{~V}$, whereas the peak current increases significantly up to the CMC, and after this value remains constant. In the vicinity of $\mathrm{CMC}$, the AA anion and the cationic surfactant coexist in solution in dynamic equilibrium, which starts an attachment of the anion radical to the micelle. At the $\mathrm{CMC}$, in the present study, estimated by cyclic voltammetry, micellization occurs. The micellar assembly can be formed by a positively charged polar head group of a surfactant locate in the interfacial region of the micelle, and in its external core are ascorbic acid molecules (ascorbate anions) that bind by electrostatic interactions. The hydrophilic region of AA directed to the water phase can be responsible for an oxidation process facilitated by CPC in the formed micellar complex. From the parameters $E_{\mathrm{pa}}$ and $I_{\mathrm{pa}}$, their dependency on the concentration and charge of the surfactant was also observed. The charge effect can be explained by an electrostatic effect, which increasing the facility to AA reaches the electrode surface. After the CMC is observed, a plateau apperars in the plot of $E_{\mathrm{pa}}$ and $I_{\mathrm{pa}}$ against the surfactant 


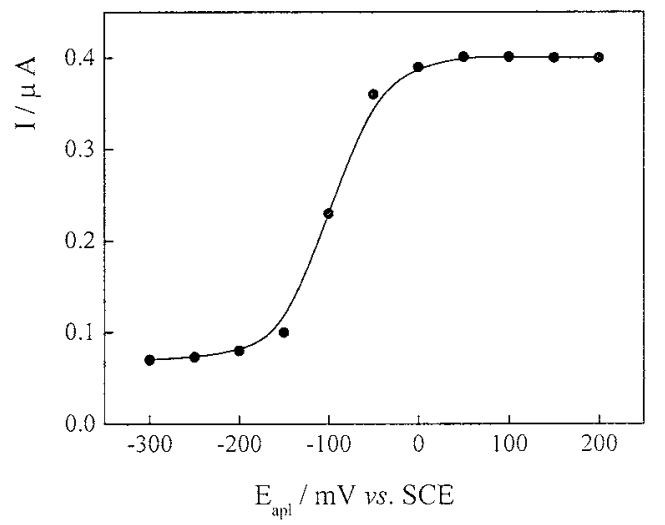

Fig. 5 Relationship between the steady state current and the applied potential $\left(E_{\text {app }}\right)$ toward $50 \mu \mathrm{mol} \mathrm{L}^{-1} \mathrm{AA}$ at $\mathrm{pH} 7.0$ in the presence of $0.1 \mathrm{~mol} \mathrm{~L}^{-1} \mathrm{CPC}$.

concentration. An excess of the surfactant influences the electron-transfer process of AA, probably by the increasing viscosity of solution, which in turn retards diffusion of the micellar complex to the electrode surface. Thus, as shown in Fig. 4, it is possible to verify that a CPC concentration of 1.0 mmol L ${ }^{-1}$ was sufficent to reach the CMC. Hence, this value was chosen for further experiments.

\section{Amperometric response of ascorbic acid}

According to the obtained results from cyclic voltametry, CPC may be successfully used for the determination of AA at a glassy carbon electrode. Figure 5 shows a plot of the steady state current against the applied potential $\left(E_{\text {app }}\right)$ for $50 \mu \mathrm{mol} \mathrm{L}{ }^{-1}$

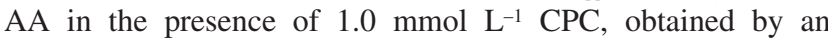
amperometric technique. As can be seen, the applied potential of $0 \mathrm{~V}$ against saturated calomel electrode (SCE) is sufficient to reach the maximum response for $\mathrm{AA}$ in the $\mathrm{CPC}$ micellar medium. In this way, an applied potential at $0 \mathrm{~V}$ was chosen, and hydrodynamic amperometry was employed to determine AA by the standard addition method in urine samples.

Figure 6 displays the amperometric curve obtained by successively adding of AA to the buffer solution. The electrode response time was $0.2 \mathrm{~s}$ for a solution of $50 \mu \mathrm{mol} \mathrm{L} \mathrm{L}^{-1} \mathrm{AA}$ in the presence of CPC. The response time was about 35-times higher than in the absence of CPC under the same conditions of the potential and the concentration.

The current of AA at the glassy carbon electrode in the presence of $1.0 \mathrm{mmol} \mathrm{L}^{-1} \mathrm{CPC}$ was linearly dependent at the AA concentration in the range $5.0 \times 10^{-7}-4.3 \times 10^{-4} \mathrm{~mol} \mathrm{~L}^{-1}$ with a detection limit of $2.0 \times 10^{-7} \mathrm{~mol} \mathrm{~L}^{-1}$, calculated according to IUPAC. ${ }^{36}$ The obtained equation was $I(\mu \mathrm{A})=0.05( \pm 0.01)+$ $0.017( \pm 0.001) C_{\mathrm{AA}}$ with a satisfatory correlation coefficient $(r=0.9996)(n=37)$, where $C_{\mathrm{AA}}$ is the AA concentration in $\mu \mathrm{mol} \mathrm{L} \mathrm{L}^{-1}$. The good performance of the proposed method can be confirmed after comparisons with those electroanalytical methods previously reported (Table 1). It is possible to verify a similar or lower limit of detection than of other methods, but the main highlight of the proposed method is attributed to the simplicity and inclusion at a clean chemistry concept, since the measurements were made in an aqueous micellar medium. The precision was estimated from a series of 10 repetitive measurements of 40 and $200 \mu \mathrm{mol} \mathrm{L} \mathrm{L}^{-1} \mathrm{AA}$ solutions. The relative standard deviations (RSD) were 1.5 and $0.5 \%$, respectively. The results suggest that the proposed method has excellent precision for the determination of AA in the presence of CPC.

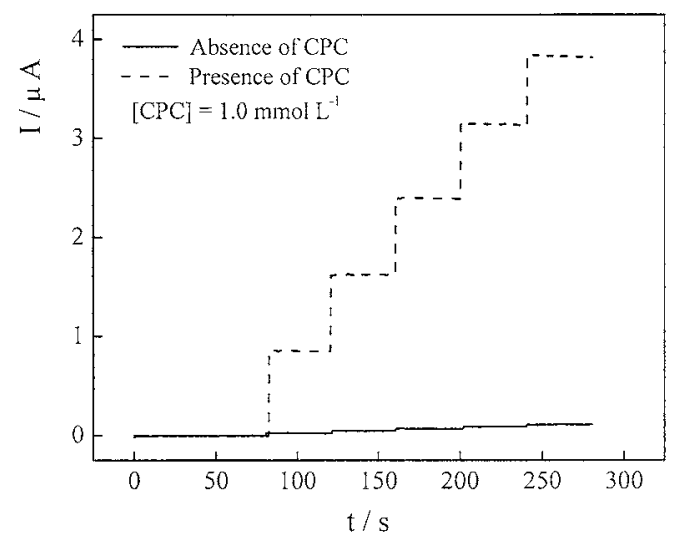

Fig. 6 Dynamic response of a glassy carbon electrode in $0.1 \mathrm{~mol}$ $\mathrm{L}^{-1}$ phosphate buffer ( $\mathrm{pH}$ 7.0) in the absence (solid line) and the presence (dashed line) of $1.0 \mathrm{mmol} \mathrm{L}-1$ CPC to five additions of 50 $\mu \mathrm{mol} \mathrm{L}-1$ AA at a constant potential of $0.0 \mathrm{~V} v$ s. SCE. Rotating speed, $200 \mathrm{rpm}$.

\section{Interference}

Usually uric acid is the major interference in the determination of AA, and this interference compound was investigated using the present method. Figure 7 shows the differential pulse voltammogram of a human urine sample diluted 100 times in a phosphate buffer solution ( $\mathrm{pH}$ 7.0) without any previous treatment. The study reveals that no peak corresponding to uric acid is observed in the potential range from -0.2 to $0.15 \mathrm{~V}$ (Fig. 7, line dashed) in the absence of $\mathrm{AA}$ and in the presence of 1.0 mmol L-1 CPC. After the addition of a $40 \mu \mathrm{mol} \mathrm{L}{ }^{-1}$ AA solution in this sample, a distinct peak was obtained at $-40 \mathrm{mV}$, corresponding to AA. When uric acid was added to the sample, a new oxidation peak corresponding to the oxidation of uric acid appeared at around $0.2 \mathrm{~V}$ (data not shown), indicanting that there was no interference on the AA response. Thus, in this condition AA can be determined without any interference of uric acid, which demonstrates selective detection of the method.

\section{Determination of AA in human urine samples}

The proposed method was applied to determinate AA by amperometry in standard urine samples supplied from Hospital UNICAMP. Urine samples were analyzed without previous purifications, and an aliquot was added into the electrochemical cell. The standard addition technique was employed for AA determination, and recovery tests checked the accuracy of the proposed method. The results of the AA values were determined in three amounts of human urine samples, which are given in Table 2. As shown, the results for the AA concentration obtained by the proposed method presented good recovery values $(98-105 \%)$. Thus, these results indicate the feasibility of the method for AA determination in complex samples, like urine.

\section{Conclusions}

The presence of positively charged CPC is responsible to control the electrode reactions of AA, shifting its oxidation potential toward more negative values. Thus, the oxidation process of AA at GCE is facilitated by its electrostatic interaction with the surfactant molecules. By considering the analytical features of the method, it is possible to conclude that advantageous characteristics have been presented when compared to those 
Table 1 Comparative data about different electroanalytical methods for the AA determination

\begin{tabular}{|c|c|c|c|c|}
\hline Modified electrode & Linear range $/ \mathrm{mol} \mathrm{L}^{-1}$ & $\mathrm{LOD} / \mathrm{mol} \mathrm{L}^{-1}$ & Sample & Ref. \\
\hline Poly(glutamic acid) chemically modified electrode & $1.2 \times 10^{-7}-2.5 \times 10^{-4}$ & $4.0 \times 10^{-8}$ & Pharmaceutical formulation & 1 \\
\hline $\begin{array}{l}\text { Carbon paste electrode modified with copper(II) } \\
\text { phosphate immobilized in a polyester resin }\end{array}$ & $2.0 \times 10^{-5}-3.2 \times 10^{-3}$ & $1.0 \times 10^{-5}$ & Pharmaceutical formulation & 5 \\
\hline $\begin{array}{l}\text { Electrodeposited redox polymer film modified gold } \\
\text { electrode }\end{array}$ & $2.0 \times 10^{-6}-4.0 \times 10^{-4}$ & $6.0 \times 10^{-7}$ & Human urine sample & 13 \\
\hline 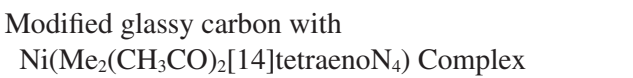 & $3.1 \times 10^{-7}-6.2 \times 10^{-3}$ & $3.1 \times 10^{-7}$ & $\begin{array}{l}\text { Commercial pharmaceutical } \\
\text { tablet, injection and food }\end{array}$ & 14 \\
\hline $\begin{array}{l}\text { Octacyanomolybdate-doped-poly(4-vinylpyridine) } \\
\text { modified electrode }\end{array}$ & $1.1 \times 10^{-5}-9.8 \times 10^{-4}$ & $5.5 \times 10^{-6}$ & $\begin{array}{l}\text { Pharmaceutical formulation } \\
\text { and orange juice }\end{array}$ & 19 \\
\hline $\begin{array}{l}\text { Glassy carbon electrode modified with a cellulose } \\
\text { acetate film bearing 2,6-dichlorophenolindophenol }\end{array}$ & $2.0 \times 10^{-5}-1.0 \times 10^{-6}$ & $1.0 \times 10^{-5}$ & $\begin{array}{l}\text { Juice and pharmaceutical } \\
\text { formulation }\end{array}$ & 32 \\
\hline $\begin{array}{l}\text { Glassy carbon electrode modified with } \\
\text { 1,5,8,12-tetraaza-2,4,9,11-tetramethylcyclotetrade } \\
\text { cyanate nickel(II) }\end{array}$ & $5.0 \times 10^{-7}-1.0 \times 10^{-3}$ & $4.7 \times 10^{-7}$ & Commercial beverage & 37 \\
\hline $\begin{array}{l}\text { Array of gold microelectrodes electrochemically } \\
\text { modified by deposition of palladium }\end{array}$ & $1.02 \times 10^{-6}-1.02 \times 10^{-5}$ & $2.86 \times 10^{-7}$ & $\begin{array}{c}\text { Beers, soda, natural juices and } \\
\text { commercial vitamin } \mathrm{C} \text { tablet }\end{array}$ & 38 \\
\hline $\begin{array}{l}\text { Carbon paste electrode spiked with ferrocene } \\
\text { carboxylic acid (FCAMCPE) }\end{array}$ & $3.48 \times 10^{-5}-0.49 \times 10^{-3}$ & $1.08 \times 10^{-5}$ & $\begin{array}{l}\text { Pharmaceutical product and } \\
\text { fruit juice }\end{array}$ & 39 \\
\hline $\begin{array}{l}\text { Screen printed carbon electrode (SPCE) } \\
\text { impregnated with the electrocatalyst 2,6-dichloro- } \\
\left.\text { phenolindophenol lanthanum salt ([DCPI }]_{3} \mathrm{La}\right)\end{array}$ & $5.0 \times 10^{-7}-4.3 \times 10^{-4}$ & $1.0 \times 10^{-5}$ & $\begin{array}{l}\text { Pharmaceutical sample and } \\
\text { orange juice }\end{array}$ & 40 \\
\hline $\begin{array}{l}\text { Carbon paste electrode modified with iron(III) ions } \\
\text { adsorbed on humic acid }\end{array}$ & $00.0-1.4 \times 10^{-3}$ & ND & Orange juice & 41 \\
\hline Bare glassy carbon electrode & $5.0 \times 10^{-7}-4.3 \times 10^{-4}$ & $2.0 \times 10^{-7}$ & Human urine sample & This work \\
\hline
\end{tabular}

LOD, limit of detection; ND, not detected.

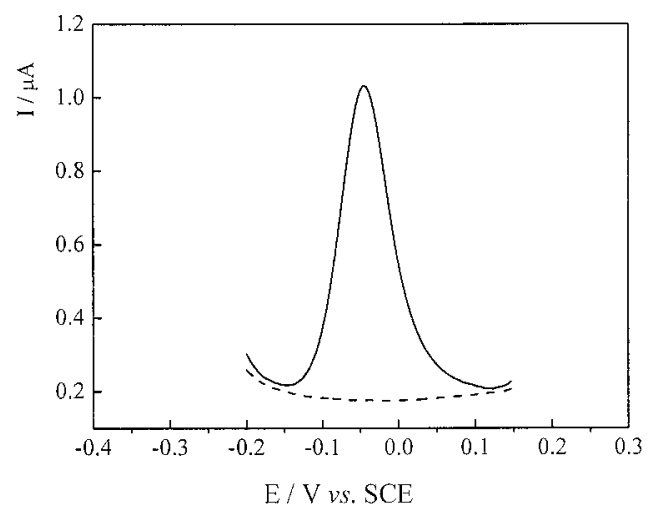

Fig. 7 Differential pulse voltammograms obtained for human urine samples (diluted 250 times) in $0.1 \mathrm{~mol} \mathrm{~L}^{-1}$ phosphate buffer ( $\mathrm{pH} 7.0$ ) and $10 \mathrm{mmol} \mathrm{L}^{-1} \mathrm{CPC}$ in the absence (dashed line) and presence (solid line) of $40 \mu \mathrm{mol} \mathrm{L}{ }^{-1}$ of AA. Potential amplitude of $50 \mathrm{mV}$. Step potential of $5 \mathrm{mV}$.

methods based on chemically modified electrode, mainly due to simplicity, since it uses a glassy carbon electrode without any modification. The electrode response was stable, and no adsorption effect was observed due to the surfactant. Satisfactory values found in recovery tests corroborate the applicability of the developed method for the quantitative determination of AA in complex samples.

\section{Acknowledgements}

The authors thank FAPESP, FAPEMIG and CNPq for financial support.
Table 2 Determination of AA in standard urine samples by the proposed method

\begin{tabular}{lcccccc}
\hline & \multicolumn{2}{c}{ Sample 1 } & \multicolumn{2}{c}{ Sample 2 } & \multicolumn{2}{c}{ Sample 3 } \\
\hline Added $/ \mu \mathrm{mol} \mathrm{L}^{-1}$ & 40.0 & 80.0 & 40.0 & 80.0 & 40.0 & 80.0 \\
${\text { Founda } / \mu \mathrm{mol} \mathrm{L}^{-1}}^{4}$ & $42 \pm 2$ & $82 \pm 2$ & $39 \pm 1$ & $80 \pm 1$ & $40 \pm 1$ & $82 \pm 1$ \\
Recovery, \% & $105 \pm 5$ & $103 \pm 3$ & $98 \pm 2$ & $99 \pm 2$ & $101 \pm 3$ & $102 \pm 2$ \\
\hline
\end{tabular}

a. Standard deviation for three replicates.

\section{References}

1. A. M. Yu and H. Y. Chen, Anal. Chim. Acta, 1997, 344, 181.

2. A. H. Liu and J. Anzai, Anal. Bioanal. Chem., 2004, 380, 98.

3. D. R. Shankaran, K. Limura, and T. K. Sato, Sens. Actuators, B, 2003, 94, 73 .

4. S. X. Zhang, Y. Q. Fu, and C. Q. Sun, Electroanalysis, 2003, 15, 739 .

5. M. F. S. Teixeira, L. A. Ramos, O. F. Filho, and E. T. G. Cavalheiro, Anal. Bioanal. Chem., 2003, 376, 214.

6. N. Gan, R. Cai, and Z. Lin, Anal. Chim. Acta, 2002, 466, 257.

7. G. M. Greenway and P. Ongomo, Analyst, 1990, 115, 1297.

8. T. P. Ruiz, C. M. Lozano, and V. Tomás, J. Fenol, Analyst, 2001, 126, 436.

9. R. Leubolt and H. Klein, J. Chromatogr., A, 1993, 640, 271.

10. N. Lenghor, J. Jakmunee, M. Vilen, R. Sara, G. D. Christian, and K. Grudpan, Talanta, 2002, 58, 1139.

11. S. P. Arya, M. Mahajan, and P. Jain, Anal. Chim. Acta, 2001, 427, 245.

12. J. Wang, Z. Wu, J. Tang, R. Teng, and E. Wang, Electroanalysis, 2001, 13, 1093.

13. J. Fei, L. Luo, S. Hu, and Z. Gao, Electroanalysis, 2004, 16,319 . 
14. M. K. Motlagh and M. Noroozifar, Anal. Sci., 2003, 19, 1671.

15. C. R. Raj, K. Tokuda, and T. Ohsaka, Bioelectrochemistry, 2001, 53, 183.

16. L. Zhang and S. J. Dong, J. Electroanal. Chem., 2004, 568, 189.

17. J. B. Raoof, R. Ojani, and S. R. Nadimi, Electrochim. Acta, 2004, 49, 271.

18. S. Wang and D. Du, Sens. Actuators, B, 2004, 97, 373.

19. R. Thangamuthu, S. M. S. Kumar, and K. C. Pillai, Sens. Actuators, B, 2007, 120, 745.

20. L. Tian, L. Chen, L. Liu, N. Lu, W. Song, and H. Xu, Sens. Actuators, B, 2007, 113, 150

21. K. Wang, J. Xu, K. Tang, and H. Chen, Talanta, 2005, 67, 798.

22. R. S. Freire and L. T. Kubota, Analyst, 2002, 127, 1502.

23. J. F. Rusling, Acc. Chem. Res., 1991, 24, 75.

24. U. Sivagnam and M. Palaniandavar, J. Electroanal. Chem., 1996, $410,43$.

25. R. Vittal, H. Gomathi, and K. J. Kim, Adv. Colloid Interface Sci., 2006, 119, 55.

26. X. L. Wen, Y. H. Jia, and Z. L. Liu, Talanta, 1999, 50, 1027.

27. M. Szymula and J. Narkiewicz-Michalek, Colloid Polym. Sci., 2003, 281, 1142.

28. P. R. Roy, M. S. Saha, T. Okajima, and T. Osaka, Electroanalysis, 2004, 16, 289.

29. P. R. Roy, T. Okajima, and T. Ohsaka, Bioelectrochemistry,
2003, 59, 11

30. G. N. Kamau, T. Leipert, S. Shukla, and J. R. Rusling, J. Electroanal. Chem., 1987, 233, 173.

31. J. F. Rusling, Colloids Surf., 1997, 123 - 124, 81.

32. A. B. Florou, M. I. Prodromidis, M. I. Karayannis, and S. M. T. Karayanni, Anal. Chim. Acta, 2000, 409, 113.

33. X. Han, J. Tang, J. Wang, and E. Wang, Electrochim. Acta, 2001, 46, 3367.

34. A. B. Mandal and B. U. Nair, J. Phys. Chem., 1991, 95, 9008.

35. Z. Zang, Q. Liang, Y. Wang, and G. Luo, J. Electroanal. Chem., 2003, 540, 29.

36. G. L. Long and J. D. Winefordner, Anal. Chem., 1983, 55, 712 .

37. Z. U. Bae, J. H. Park, S. H. Lee, and H. Y. Chang, J. Electroanal. Chem., 1999, 468, 85.

38. L. Angnes, R. C. Matos, M. A. Augelli, J. J. Pedrotti, and C. L. Lago, Electroanalysis, 1998, 10, 1.

39. J.-B. Raoof, R. Ojani, and A. Kiani, J. Electroanal. Chem., 2001, 515, 45.

40. A. B. Florou, M. I. Prodromidis, S. M. TzouwaraKarayanni, and M. I. Karayannis, Anal. Chim. Acta, 2000, 423, 107.

41. S. Silva, T. N. Oliveira, M. A. Ballin, and C. R. M. Peixoto, Eclet. Quim., 2006, 31, 39. 